\title{
$\beta$-catenin activation is not involved in sporadic parathyroid carcinomas and adenomas
}

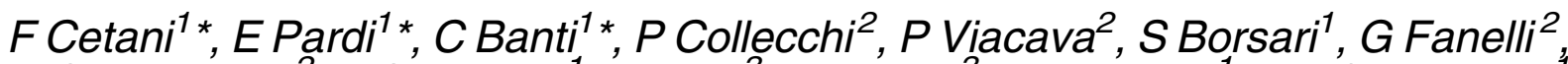 \\ A G Naccarato ${ }^{2}, F_{\text {Saponaro }}{ }^{1}$, S Berti $^{3}$, P Miccoli $^{3}$, A Pinchera $^{1}$ and C Marcocci $^{1}$
}

\author{
${ }^{1}$ Department of Endocrinology and Metabolism, ${ }^{2}$ Department of Oncology, Section of Pathology and ${ }^{3}$ Department of Surgery, \\ University of Pise, Pise, Italy \\ (Correspondence should be addressed to $\mathrm{F}$ Cetani who is now at Dipartimento di Endocrinologia e Metabolismo, Università di Pisa, \\ Via Paradisa 2, 56124 Pisa, Italy; Email: cetani@endoc.med.unipi.it) \\ *(F Cetani, E Pardi and C Banti contributed equally to this work)
}

\begin{abstract}
Aberrant accumulation of $\beta$-catenin has been found in various types of human tumors. The aim of this study was to evaluate whether Wnt/ $\beta$-catenin signaling is activated in parathyroid carcinomas and adenomas. We studied 154 parathyroid tumors (18 carcinomas (13 with distant metastases), six atypical adenomas, and 130 adenomas). Three normal parathyroid tissues were used as control. Direct sequencing of exon 3 of the CTNNB1 gene showed absence of stabilizing mutations in all the tumors. Immunostaining of $\beta$-catenin was performed in all carcinomas and in 66 adenomas (including three atypical). Normal parathyroid showed a homogeneous distinct outer cell membrane staining in the majority of cells and no nuclear staining. A weak cytoplasmic staining was observed in one case. All tumors showed negative nuclear staining. With the exception of one carcinoma, which had a negative membrane staining, all other samples showed a membrane staining which was similar to that of the normal parathyroid. $\beta$-Catenin expression was heterogeneous with a range of positive cells between 5 and $80 \%$, independently of tumor type. Our results suggest that the $W n t / \beta$-catenin signaling pathway is not involved in the development of parathyroid carcinomas and adenomas.
\end{abstract}

Endocrine-Related Cancer (2010) 17 1-6

\section{Introduction}

Parathyroid carcinoma is a rare endocrine malignancy and accounts for $<1 \%$ of cases of sporadic primary hyperparathyroidism (PHPT) (Marcocci et al. 2008). Oncogenes and tumor suppressor genes have been linked to parathyroid carcinomas, especially those involved in the control of the cell cycle (Arnold et al. 2002). The hyperparathyroidism-jaw tumor syndrome, in which a high prevalence of parathyroid cancer is present, has provided the best evidence for a defined gene in parathyroid cancer (Carpten et al. 2002). The gene is known as CDC73 or HRPT2 and mutations have been identified in about $70 \%$ of cases of sporadic parathyroid carcinomas (Shattuck et al. 2003, Cetani et al. 2004, Howell et al. 2003). HRPT2 encodes a protein of 531 amino acids called parafibromin.
Parafibromin is a tumor suppressor protein and has recently been linked to $\mathrm{Wnt} / \beta$ catenin pathway (Mosimann et al. 2006).

Activation of the $\mathrm{Wnt} / \beta$-catenin pathway is involved in a variety of human neoplasms (Polakis 2007). In the absence of Wnt signaling, $\beta$-catenin is phosphorylated and degraded by a protein complex consisting of adenomatosis polyposis coli (APC), axin and glycogen synthase kinase-3 $\beta$ (GSK-3 $\beta$ ), leading to its proteosomal degradation. The activation of Wnt signaling inhibits GSK-3 $\beta$ activity evoking aberrant $\beta$-catenin accumulation in the nucleus and activation of related target genes. Alterations of the different proteins involved in the $\mathrm{Wnt} / \beta$-catenin signaling may lead to nuclear accumulation of $\beta$-catenin and activation of gene transcription (Polakis 2007). CTNNB1 gene 
encodes $\beta$-catenin and most mutations detected so far in human tumors are located in exon 3 , encoding the GSK-3 $\beta$ recognition motif and generally involve serine-threonine phosphorylation sites or adjacent residues, making this a 'hotspot' (Polakis 2007).

Previous studies evaluated the role of the $\mathrm{Wnt} / \beta$-catenin pathway in benign parathyroid tumors and mostly provided negative results (Semba et al. 2000, Ikeda et al. 2002, Costa-Guda \& Arnold 2007). Conversely, Björklund et al. (2007, 2008) reported cytoplasmic/nuclear accumulation of $\beta$-catenin in parathyroid adenomas and secondary hyperplasic glands, and stabilizing mutation (S37A) in exon 3 of the CTNNB1 gene in about $7 \%$ of adenomas. Juhlin et al. (2009) have recently investigated by immunohistochemistry the expression of $\beta$-catenin in parathyroid carcinomas and, in contrast, found a similarly positive cytoplasmic and nuclear staining in carcinomas and adenomas as was found in the normal rim of adenomas. Mutational analysis of CTNNB1 gene in these tumors was not performed.

The aim of the present study was to further investigate by mutational analysis of exon 3 of the $C T N N B 1$ gene and $\beta$-catenin immunohistochemistry the role of the $\beta$-catenin in the pathogenesis of parathyroid carcinomas and address the discrepancy in published results on CTNNB1 mutations and expression in benign parathyroid adenomas.

\section{Materials and methods}

\section{Tissue samples}

Parathyroid specimens consisted of 18 carcinomas (13 with distant metastases), six atypical adenomas and 130 adenomas from sporadic PHPT patients of Italian origin. Histopathological classification was according to the guidelines of the World Health Organization (DeLellis et al. 2006). Atypical adenoma was defined by histological features such as trabecular growth, mitoses, and fibrous band in the absence of definite capsular and vascular invasion (DeLellis et al. 2006). Normal parathyroid tissue of normocalcemic Italian patients (paraffin-embedded $(n=3)$ inadvertently removed at thyroid surgery; frozen biopsies $(n=2)$ from patients operated on for nodular goiter) was used as control. Tissues were obtained at surgery, immediately snap frozen in liquid nitrogen and stored at $-80{ }^{\circ} \mathrm{C}$ until use, or retrieved from pathological archives. Informed consent and approval by our Institutional Review Board were obtained.

\section{Genetic analyses}

All samples were tested for exon 3 of CTNNB1 (GenBank accession no. NM_001904) mutations. Genomic DNA was isolated by standard methods. The region of interest was amplified by PCR with the following primers: forward primer, $5^{\prime}$-CAT TTC CAA TCT ACT AAT GCT; and reverse, $5^{\prime}$-CTG CAT TCT GAC TTT CAG TAA. Both strands of the PCR fragments were sequenced directly on an auto sequencer (ABI PRISM 310, Genetic Analyzer, Applied Biosystems Inc.).

\section{Immunohistochemistry}

Immunostaining studies were performed using paraffin-embedded sections of three normal parathyroids, 18 carcinomas, three of the six atypical adenomas and 63 of the 130 adenomas which were all analyzed for CTNNB1 mutations. We could not use the other tissue samples because they were not available any longer as they have been used for other experiments. Sideby-side immunohistochemistry was also performed in paraffin-embedded and frozen tissue specimens from the same cases (two normal parathyroid biopsies and 15 parathyroid adenomas).

Sections were deparaffinized in xylene and rehydrated in alcohol. Endogenous peroxide activity was blocked by incubating the slides in $1 \%$ hydrogen peroxide in methanol for $10 \mathrm{~min}$. In order to unmask the antigen, the slides were microwave-treated in $10 \mathrm{mM}$ citrate buffer, $\mathrm{pH} 6.0$ for $10 \mathrm{~min}$. After blocking nonspecific staining with normal serum the sections were incubated for $1 \mathrm{~h}$ with the primary anti- $\beta$-catenin monoclonal antibody (dilution 1:50) raised against the C-terminus (Dako Diagnostics, Carpinteria, CA, USA). The sections were then incubated with biotin-labeled secondary antibody (dilution 1:500) and avidin-biotin complex (Vector, Burlingame, CA, USA) for $30 \mathrm{~min}$ each. Sites of binding were visualized using 3,3diaminobenzidine as chromogen. Finally, sections were counterstained with hematoxylin, dehydrated, and mounted. Positive and negative controls were breast ductal carcinoma, typically showing a distinct membrane staining, and experiments in which the primary antibody was omitted respectively. Staining of nucleus, cytoplasm, and outer membrane was evaluated and separately quantified according to the percentage of positive cells, independently of the intensity of staining. Each section was evaluated by two independent observers without knowledge of the diagnosis. In a few cases where the assessment differed between the two observers, the disagreements were resolved by reaching a consensus after joint review using 
a conference microscope. For frozen tissue immunostaining 5-micron-thick sections of either normal or pathological tissues were prepared in a cryostat and stored at $-80{ }^{\circ} \mathrm{C}$ before use. Frozen sections were airdried and then fixed for $10 \mathrm{~min}$ in $4 \%$ formaldehyde at room temperature. All subsequently steps were similar to those using paraffin-embedded samples.

\section{Results}

\section{Genetic analysis of the CTNNB1 gene}

To investigate the potential role of the Wnt- $\beta$-catenin pathway in the pathogenesis of parathyroid carcinomas, we first screened genomic DNA from 18 parathyroid carcinomas for mutations in exon 3 of CTNNB1 gene. No mutations were detected in these tumors.
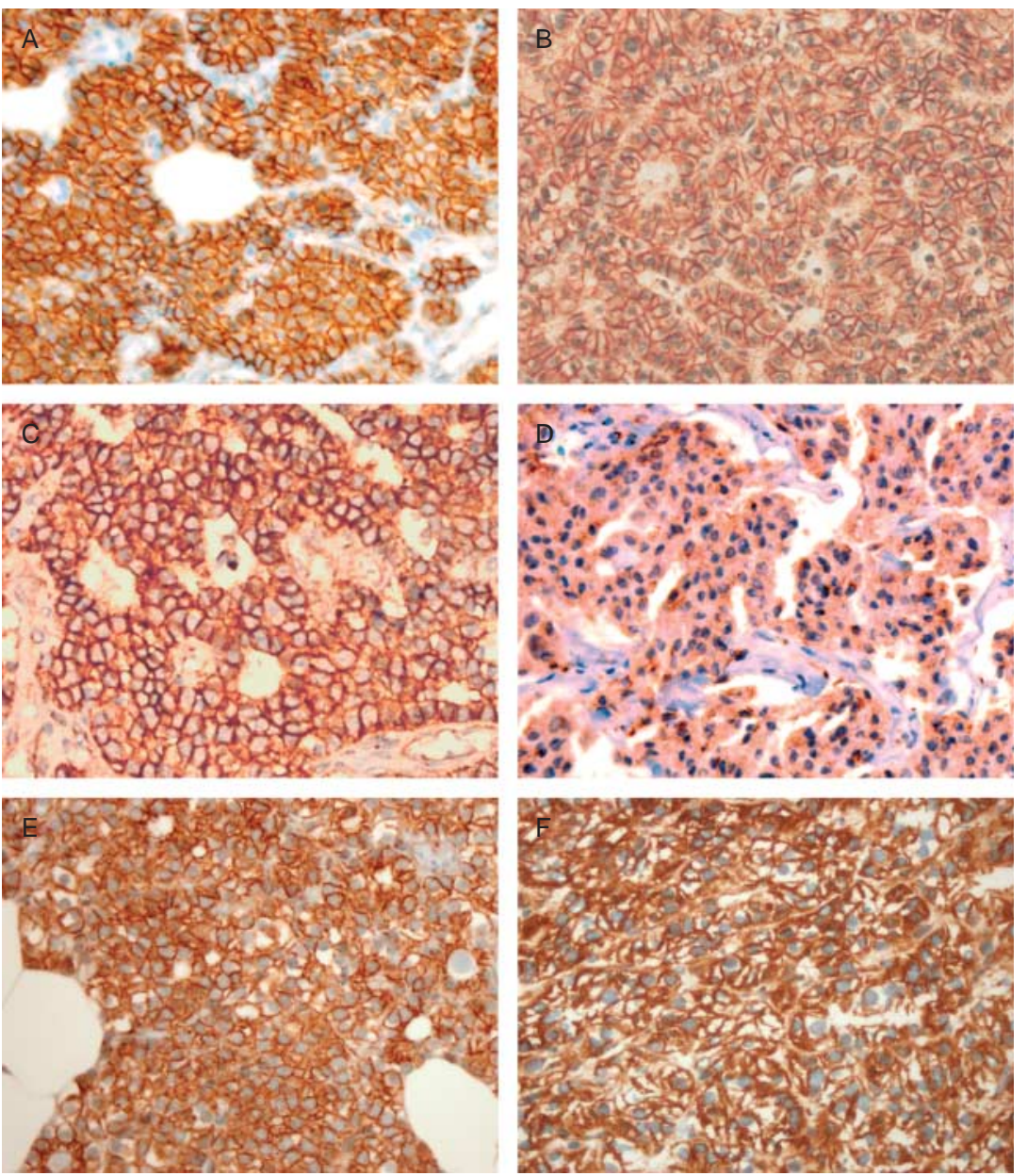

Figure $1 \beta$-Catenin immunohistochemistry in paraffin-embedded (A-D) and frozen tissue samples (E and $F$ ). A distinct homogeneous outer membrane staining is evident in normal parathyroid ( $A$ and $E ; \times 400)$, parathyroid adenoma (B and $F ; \times 250)$ and carcinoma $(C ; \times 250)$. Lack of outer membrane staining in a parathyroid carcinoma $(D ; \times 150)$. All samples show negative staining in the nucleus. 
Table 1 Results of $\beta$-catenin immunohistochemistry in parathyroid tumors ${ }^{a}$

\begin{tabular}{lrrrr}
\hline & & & Positive staining $^{\mathrm{b}}$ \\
\cline { 3 - 5 } & $N$ & Outer cell membrane & Cytoplasm $^{\text {c }}$ & \\
\hline Carcinomas & & & & \\
With metastases & 13 & $12(6)$ & $3(0)$ & 0 \\
Without metastases & 5 & $5(1)$ & $7(0)$ & 0 \\
Adenomas & 63 & $63(41)$ & $0(0)$ & 0 \\
Atypical adenomas & 3 & $3(2)$ & 0 & 0 \\
\hline
\end{tabular}

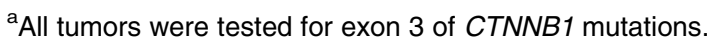

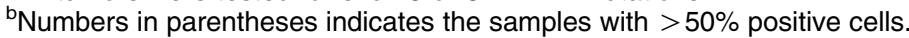

'Weak granular staining.

A summary of $\beta$-catenin immunostaining in parathyroid tumors is reported in Table 1. Representative cases are shown in Fig. 1. All parathyroid carcinomas and adenomas showed a negative nuclear staining. With the exception of one carcinoma, which had a negative membrane staining, all other samples showed a membrane staining which was similar to that of the normal parathyroid. $\beta$-Catenin expression was heterogeneous with a range of positive cells between 5 and $80 \%$, independently of tumor type. A weak granular cytoplasmic staining was present in 12 of $81(14.8 \%)$ samples (five of 18 carcinomas and seven of 63 adenomas). There was no relationship between cytoplasmic and cell membrane staining. All frozen parathyroid adenomas also showed a negative nuclear staining. A distinct membrane staining, which was similar to that of normal parathyroid biopsies, was observed (Fig. 1).

\section{Discussion}

The results of the present investigation show lack of CTNNB1 gene mutations in a series of sporadic parathyroid carcinomas and adenomas. To our knowledge no study has previously searched for these mutations in parathyroid malignancy. Five studies by four groups performed in different countries have previously looked for CTNNB1 mutations in parathyroid adenomas (Semba et al. 2000, Ikeda et al. 2002, Björklund et al. 2007, 2008, Costa-Guda \& Arnold 2007). Negative results were reported in Japanese (Semba et al. 2000, Ikeda et al. 2002) and American (Costa-Guda \& Arnold 2007) series. On the other hand, Björklund et al. (2007, 2008), in a Swedish population, found a somatic homozygous S37A substitution in exon 3 of CTNNB1 gene in nine out of $124(7.3 \%)$ adenomas (Table 2).

Even in the absence of $C T N N B 1$ gene mutations, an activation of the $\mathrm{Wnt} / \beta$-catenin signal in parathyroid carcinomas may result from abnormalities of other components of this pathway, namely APC, axin GSK-3 $\beta$, and other proteins. To investigate this possibility we looked for alterations of $\beta$-catenin expression by immunohistochemistry. The results of the present study show absent nuclear $\beta$-catenin staining suggesting that there is no activation of this pathway in parathyroid carcinoma. As a matter of fact the parathyroid carcinomas displayed the same membrane and weak cytoplasmic staining observed in the normal parathyroid tissue. Our data are in agreement with those recently reported by Juhlin et al. (2009) using a C-terminus antibody similar to the one used by us. Conversely, when using an antibody against the active $\beta$-catenin, Juhlin et al. (2009) detected a cytoplasmic and nuclear staining in parathyroid carcinomas, but this pattern was comparable with that observed in normal parathyroid rims.

We also found absent nuclear expression of $\beta$-catenin in parathyroid adenomas. A summary of the published data on $\beta$-catenin immunostaining are reported in Table 2. Björklund et al. $(2007,2008)$ reported a specific nuclear staining in all parathyroid adenomas, but not in the normal parathyroid. However, at least looking at the picture reporting the staining of 84 parathyroid adenomas (Fig. 3 in Björklund et al. 2008), we are not sure that it provides clear and convincing evidence of nuclear staining and may warrant further scrutiny. In the other studies (Ikeda et al. 2000, Semba et al. 2000, Juhlin et al. 2009, Cetani et al. present study) with the exception of one parathyroid adenoma, no tumors showed abnormal (nuclear) $\beta$-catenin expression as compared with normal parathyroid tissue. The nuclear expression detected by Juhlin et al. (2009) in parathyroid adenomas using an antibody against active $\beta$-catenin was similar to that observed in normal parathyroid tissue.

The reasons for discrepant data on $\beta$-catenin status in parathyroid adenomas are unclear. As far as mutational analysis, the different results might be related to chance clustering with a low somatic mutation frequency of 
Table 2 Summary of $\beta$-catenin mutation (exon 3) and immunohistochemical studies in normal parathyroid tissue and parathyroid tumors

\begin{tabular}{|c|c|c|c|c|}
\hline \multirow[b]{2}{*}{ Author } & \multirow[b]{2}{*}{$n$} & \multirow[b]{2}{*}{ Mutation } & \multicolumn{2}{|c|}{ Nuclear expression } \\
\hline & & & C-term $\beta$-catenin & Active $\beta$-catenin \\
\hline \multicolumn{5}{|l|}{ Normal parathyroid tissue } \\
\hline Semba et al. (2000) & & - & Negative & $N D^{a}$ \\
\hline lkeda et al. (2002) & & - & Negative & ND \\
\hline Björklund et al. (2007) & 6 & - & Negative & Negative \\
\hline Juhlin et al. $(2009)^{\mathrm{b}}$ & 12 & - & Negative & Positive $^{c}$ \\
\hline Cetani (present study) & 3 & - & Negative & ND \\
\hline \multirow[t]{2}{*}{ Total } & 21 & & $0 / 21$ & $12 / 18$ \\
\hline & & & \multicolumn{2}{|c|}{ Abnormal nuclear expression } \\
\hline Author & $n$ & Mutation & C-term $\beta$-catenin & Active $\beta$-catenin \\
\hline \multicolumn{5}{|l|}{ Carcinomas } \\
\hline Semba et al. (2000) & 1 & $N D^{a}$ & $0 / 1$ & ND \\
\hline Juhlin et al. (2009) & 13 & ND & $0 / 13$ & $0 / 13^{\mathrm{b}, \mathrm{c}}$ \\
\hline Cetani (present study) & 18 & $0 / 18$ & $0 / 18$ & ND \\
\hline Total & 32 & $0 / 18$ & $0 / 32$ & $0 / 13$ \\
\hline \multicolumn{5}{|l|}{ Atypical adenomas } \\
\hline Cetani et al. (present study) & 6 & $0 / 6$ & $0 / 3$ & ND \\
\hline \multicolumn{5}{|l|}{ Adenomas } \\
\hline Semba et al. (2000) & 9 & $0 / 1$ & $1 / 9^{c}$ & ND \\
\hline Ikeda et al. (2002) & 24 & $0 / 24$ & $0 / 24$ & ND \\
\hline Costa-Guda \& Arnold (2007) & 97 & $0 / 97$ & ND & ND \\
\hline Björklund et al. (2007) & 37 & $3 / 20$ & $37 / 37$ & $37 / 37$ \\
\hline Björklund et al. (2008) & 104 & $6 / 104$ & $81 / 81$ & $81 / 81$ \\
\hline Juhlin et al. (2009) & 18 & ND & $0 / 18$ & $0 / 18$ \\
\hline Cetani (present study) & 130 & $0 / 130$ & $0 / 63$ & ND \\
\hline Total & 419 & $9 / 376(2.4 \%)$ & $119 / 232(51.3 \%)$ & $118 / 136(86.8 \%)$ \\
\hline
\end{tabular}

a Not done.

${ }^{\mathrm{b}}$ Adjacent normal rim of adenomas.

${ }^{\mathrm{c}} \mathrm{A}$ mixture of positive and negative nuclei is reported by the authors.

$C T N N B 1$, differences in the genetic background of sample populations, and dietary and environmental factors. A wide range of frequency of CTNNB1 mutations has been observed in other human tumors (reviewed in Gamallo et al. (1999)), but no relationship was reported between geographical origin and frequency of somatic mutation in colorectal cancer and melanomas (reviewed in Björklund et al. (2008)). Differences in the genetic background could, in theory but without known precedent, contribute to the different prevalence of acquired CTNNB1 mutations between the Japanese and Swedish PHPT series, but not between the latter and the American and Italian series, since they have the same genetic ancestry. Therefore, dietary and environmental factors might be at least partly responsible for such differences. As far as immunohistochemistry data, beyond the above comments on the studies of Björklund et al. possible differences in the experimental conditions should also be taken into account. Björklund et al. (2007, 2008) used frozen tissues, whereas all other authors employed paraffin-embedded materials. However, at least in our hands, $\beta$-catenin immunostaining did not differ using paraffin embedded or frozen parathyroid samples. Finally, antibodies raised against different portion of $\beta$-catenin were employed. In spite of that, similar results were reported by Björklund et al. (2007) using four antibodies, either polyclonal or monoclonal, with different specificity (anti-active or anti-C-terminus).

In conclusion, our study suggests that alterations in the $\mathrm{Wnt} / \beta$-catenin signaling pathway are not involved in the development of parathyroid carcinomas. The status of $\beta$-catenin in benign parathyroid tumors remains controversial and additional studies including tumor samples from different countries are warranted.

\section{Declaration of interest}

The authors declare that there is no conflict of interest that could be perceived as prejudicing the impartiality of the research reported. 


\section{Funding}

This work was partly supported by grants from The Ministero dell'Istruzione, dell'Università e della Ricerca, The Ministero della Salute, (to C Marcocci), and the University of Pisa (Fondi di Ateneo per la Ricerca to C Marcocci).

\section{Acknowledgements}

We thank Prof. Mauro Papotti (Department of Clinical and Biological Sciences at San Luigi Hospital, University of Turin, Orbassano, Turin, Italy) for providing five parathyroid carcinoma samples. We also thank Mr Pasquale Cofelice for technical assistance.

\section{References}

Arnold A, Shattuck TM, Mallya SM, Krebs LJ, Costa J, Gallagher J, Wild Y \& Saucier K 2002 Molecular pathogenesis of primary hyperparathyroidism. Journal of Bone and Mineral Research 7 N30-N36.

Björklund P, Akerström G \& Westin G 2007 Accumulation of nonphosphorylated $\beta$-catenin and c-myc in primary and uremic secondary hyperparathyroid tumors. Journal of Clinical Endocrinology and Metabolism 92 338-344.

Björklund P, Lindberg D, Akerström G \& Westin G 2008 Stabilizing mutation of CTNNB1/ $\beta$-catenin and protein accumulation analyzed in a large series of parathyroid tumors of Swedish patients. Molecular Cancer 7 53-60.

Carpten JD, Robbins CM, Villablanca A, Forsberg L, Presciuttini S, Bailey-Wilson J, Simonds WF, Gillanders EM, Kennedy AM, Chen JD et al. 2002 HRPT2, encoding parafibromin, is mutated in hyperparathyroidism-jaw tumors syndrome. Nature Genetics 32 676-680.

Cetani F, Pardi E, Borsari S, Viacava P, Dipollina G, Cianferotti L, Ambrogini E, Gazzerro E, Colussi G, Berti P et al. 2004 Genetic analyses of the HRPT2 gene in primary hyperparathyroidism: germline and somatic mutations in familial and sporadic parathyroid tumors. Journal of Clinical Endocrinology and Metabolism 89 5583-5591.

Costa-Guda J \& Arnold A 2007 Absence of stabilizing mutations of $\beta$-catenin encoded by CTNNB1 exon 3 in a large series of sporadic parathyroid adenomas. Journal of Clinical Endocrinology and Metabolism 92 1564-1566.
DeLellis RA, Lloid RV, Heitz PU \& Eng C 2006

Pathology and genetics of the tumors of endocrine organs. In WHO Classification of Tumors, pp 124-127. Eds RA DeLellis, RV Lloyd, PU Heitz \& C Eng. Lyon: IARC Press.

Gamallo C, Palacios J, Moreno G, Calvo de Mora J, Suarez A \& Armas A 1999 ß-Catenin expression pattern in stage I and II ovarian carcinomas. American Journal of Pathology 155 527-536.

Howell VM, Haven CJ, Kahnoski K, Khoo SK, Petillo D, Chen J, Fleuren GJ, Robinson BG, Delbridge LW, Philips J et al. 2003 HRPT2 mutations are associated with malignancy in sporadic parathyroid tumours. Journal of Medical Genetics 40 657-663.

Ikeda S, Ishizaki Y, Shimizu Y, Fujimori M, Ojima Y, Okajima M, Sugino K \& Asahara T 2002 Immunohistochemistry of cyclin D1 and $\beta$-catenin, and mutational analysis of exon 3 of $\beta$-catenin gene in parathyroid adenomas. International Journal of Oncology 20 463-466.

Juhlin CC, Haglund F, Villablanca A, Forsberg L, Sandelin K, Bränström R, Larsson C \& Höög A 2009 Loss of expression for the Wnt pathway components adenomatous polyposis coli and glycogen synthase kinase 3- $\beta$ in parathyroid carcinomas. International Journal of Oncology 34 481-492.

Marcocci C, Cetani F, Rubin MR, Silverberg SJ, Pinchera A \& Bilezikian JP 2008 Parathyroid carcinoma. Journal of Bone and Mineral Research 23 1869-1880.

Mosimann C, Hausmann G \& Basler K 2006 Parafibromin/Hyrax activates Wnt/Wg target gene transcription by direct association with $\beta$-catenin/Armadillo. Cell 125 327-341.

Polakis P 2007 The many ways of Wnt in cancer. Current Opinion in Genetics \& Development 17 45-51.

Semba S, Kusumi R, Moriya T \& Sasano H 2000 Nuclear accumulation of B-catenin in human endocrine tumors: association with Ki-67 (MIB-1) proliferative activity. Endocrine Pathology 11 243-250.

Shattuck TM, Välimäki S, Obara T, Gaz RD, Clark OH, Shoback D, Wierman ME, Tojo K, Robbins CM, Carpten JD et al. 2003 Somatic and germ-line mutations of the HRPT2 gene in sporadic parathyroid carcinoma. New England Journal of Medicine 349 1722-1729. 